\title{
Mongolian spots as a finding in forensic examinations of possible child abuse-implications for case work
}

\author{
Mattias Kettner ${ }^{1,2}$ (D) Christoph G. Birngruber ${ }^{3} \cdot$ Constanze Niess $^{1,2} \cdot$ Marco Baz-Bartels $^{2,4} \cdot$ Lena Bunzel $^{1,2}$. \\ Marcel A. Verhoff ${ }^{1,2} \cdot$ Constantin Lux ${ }^{1,2} \cdot$ Frank Ramsthaler $^{5}$
}

Received: 27 March 2019 / Accepted: 8 November 2019 / Published online: 12 March 2020

(C) The Author(s) 2020

\begin{abstract}
Mongolian spots (MS) are congenital dermal conditions resulting from neural crest-derived melanocytes migration to the skin during embryogenesis. MS incidences are highly variable in different populations. Morphologically, MS present as hyperpigmented maculae of varying size and form, ranging from round spots of $1 \mathrm{~cm}$ in diameter to extensive discolorations covering predominantly the lower back and buttocks. Due to their coloring, which is also dependent on the skin type, MS may mimic hematoma thus posing a challenge on the physician conducting examinations of children in cases of suspected child abuse. In the present study, MS incidences and distribution, as well as skin types, were documented in a collective of 253 children examined on the basis of suspected child abuse. From these data, a classification scheme was derived to document MS and to help identify cases with a need for recurrent examination for unambiguous interpretation of initial findings alongside the main decisive factors for re-examination such as general circumstances of the initial examination (e. g., experience of the examiner, lighting conditions) and given dermatological conditions of the patient (e. g., diaper rash).
\end{abstract}

Keywords Mongolian spot $\cdot$ MS $\cdot$ Child abuse $\cdot$ Forensic examination $\cdot$ Nevus of Ito $\cdot$ Nevus of Ota

\section{Introduction}

Examinations of children suspected to have suffered from child abuse have been a constantly growing field of expertise in forensic routine casework with regard to frequency and extent over the past two decades. The prevalence of children aged $0-14$ suffering from some kind of physical abuse has been estimated at $22.9 \%$ in the European Union [1]. In a

Mattias Kettner

Kettner@med.uni-frankfurt.de

1 Institute of Legal Medicine, University Hospital Frankfurt/Main, Goethe University, Frankfurt/M, Germany

2 Department of Child Protection/Kinderschutzambulanz, University Hospital Frankfurt/Main, Goethe University, Frankfurt/M, Germany

3 Institute of Legal Medicine, University Hospital Giessen, Justus Liebig University, Giessen, Germany

4 Department of Neuropediatrics, University Hospital Frankfurt/Main, Goethe University, Frankfurt/M, Germany

5 Institute of Legal Medicine, Saarland University, Homburg, Saar, Germany forensic context, examinations are usually mandated by investigative authorities or the youth welfare services. In these cases, implications of forensic expert opinion are potentially enormous including temporary or permanent removal of the child from the family home and criminal prosecution of the perpetrators. Due to the typically clandestine and domestic nature of child abuse, the number of involved persons is often limited to presumed victims of child abuse and alleged perpetrators thereof. Since many of the patients examined are infants or toddlers with limited usability of witness reports, explanatory statements concerning documented injuries are mainly constricted to alleged perpetrators and are thus also of limited value. In consideration of the aforementioned, statements claiming that a certain dermatological condition is congenital have to be scrutinized thoroughly.

Mongolian spots (MS) are a congenital dermatological condition believed to result from neural crest-derived melanocytes migrating to the skin during embryogenesis, which normally reside at the dermal-epidermal junction [2,3]. MS incidences vary highly between different populations ranging from 0.04 to $96.53 \%$ (Table 1).

They belong to the group of congenital dermal melanocytoses comprising MS, nevus of Ito (naevus fuscocoeruleus 
Table 1 Incidence of Mongolian spots in different ethnicities

\begin{tabular}{|c|c|c|c|c|c|}
\hline & $\begin{array}{l}\text { Publication } \\
\text { year }\end{array}$ & Population & Age & $\mathrm{n}$ & $\begin{array}{l}\text { Percentage of } \\
\text { MS }\end{array}$ \\
\hline \multirow[t]{4}{*}{ Cordova et al. [4] } & \multirow[t]{4}{*}{1981} & US-African Am & Newborn & 259 & 96.53 \\
\hline & & US-Hispanic & Newborn & 62 & 46.57 \\
\hline & & US-Caucasian & Newborn & 42 & 9.32 \\
\hline & & US-Asian & Newborn & 2 & 100 \\
\hline \multirow[t]{3}{*}{ Rivers et al. [5] } & \multirow[t]{3}{*}{1990} & Australian-Caucasian & Newborn & 346 & 13.3 \\
\hline & & Australian-Mongolian & Newborn & 56 & 83.9 \\
\hline & & Australian-Australasian & Newborn & 9 & 77.8 \\
\hline Karvonen et al. [6] & 1992 & Finnish & Newborn & 4346 & 0.04 \\
\hline Tsai et al. [7] & 1993 & Chinese & Newborn & 3345 & 86.3 \\
\hline $\begin{array}{l}\text { Magana-Garcia et al. } \\
\text { [8] }\end{array}$ & 1997 & Mexican & Newborn & 1000 & 77.0 \\
\hline Egemen et al. [9] & 2006 & Turkish & $\begin{array}{l}\text { 1-12 } \\
\text { months }\end{array}$ & 924 & 26.0 \\
\hline Shih et al. [10] & 2007 & Taiwanese & Newborn & 500 & 61.6 \\
\hline Fehrabas et al. [11] & 2009 & Turkish & Newborn & 816 & 13.2 \\
\hline Reza et al. [12] & 2010 & Iranian & Newborn & 2305 & 11.4 \\
\hline \multirow[t]{5}{*}{ Kanada et al. [13] } & \multirow[t]{5}{*}{2012} & US-Caucasian & Newborn & 263 & 6.7 \\
\hline & & US-Hispanic & Newborn & 116 & 25.7 \\
\hline & & US-Other & Newborn & 56 & 38 \\
\hline & & US-Asian & Newborn & 41 & 40.7 \\
\hline & & US-African Am. & Newborn & 19 & 32.1 \\
\hline Gupta et al. [14] & 2013 & Indian & Newborn & 2313 & 65.9 \\
\hline Haveri et al. [15] & 2014 & Indian & Newborn & 1000 & 84.7 \\
\hline Shehab et al. [16] & 2015 & Egyptian & Newborn & 177 & 20.5 \\
\hline Punuru et al. [17] & 2016 & Indian & Newborn & 100 & 84.0 \\
\hline Sandeep et al. [18] & 2016 & Indian & Newborn & 250 & 61.8 \\
\hline Budair et al. [19] & 2017 & Saudi-Arabian & Newborn & 313 & 63.07 \\
\hline
\end{tabular}

deltoideoacromialis), nevus of Ota (naevus fuscocaeruleus ophthalmomaxillaris), and melanocyte hamartoma [20-23]. These conditions can be distinguished primarily based on their distribution site (Table 2). Histologically, groups of spindleshaped melanocytes percolate through the reticular dermis and subcutaneous tissue in all four entities comprised under the term dermal melanocytoses [2]. Morphologically, MS present as hyperpigmented maculae of varying size and form, ranging from round spots of $1 \mathrm{~cm}$ in diameter to extensive discolorations covering predominantly the lower back and buttocks in their entirety. Despite these preferential sites, the upper back [24] and scalp [25] may also be affected. They are usually colored blue-gray to blue-green but may also shade into purple, dark blue-red and brown-black tones, which is also due to differing skin types (e.g., discoloration due to MS in skin type 1 as compared to type 6 according to Fitzpatrick [26]). Superimposition of MS [27, 28] and Café-au-lait spots [29] on MS has been described. Furthermore, MS have been associated with inherited disorders such as mucopolysaccharidosis type I (Hurler syndrome) [30, 31], GM1 gangliosidosis type I [32-34], mucopolysaccharidosis [35], type II (Hunter syndrome) [36], mucolipidosis [37],
Niemann-Pick disease [38], and $\alpha$-mannosidosis [39]. Typically, MS regress over the first years and disappear until the age of 6 years [40]. In some cases, persistence to adult age has been reported [41].

From a forensic perspective, MS may pose a challenge on the examiner to differentiate between possible signs of child abuse and dermatological condition [42-44]. This holds especially true since medical examinations in a forensic context are usually snapshots of a given status at a specific moment in time. Thus, MS may mimic a hematoma due to blunt force and may even be seen as proof of recurrent trauma in the presence of "additional" differently colored hematoma. In Central Europe with a population predominantly assigned to skin types I and II, incidences of MS in the overall population and thus the forensic examination sample are rather low. In late 2015, a pronounced increase in cases wit MS over the last year was noted, which was believed to be mainly due to examinations assigned by child welfare services on behalf of children in refugee families. Therefore, we conducted a prospective study to determine the frequency of MS in examinations of children with possible child abuse, to document possible challenges for the forensic examiner, and to 
Table 2 Typical distribution, age of onset, and clinical course of dermal melanocytoses

\begin{tabular}{|c|c|c|c|}
\hline & Typical distribution & Onset & Course \\
\hline $\begin{array}{l}\text { Mongolian } \\
\text { spots } \\
\text { (MS) }\end{array}$ & $\begin{array}{l}\text { Lower back and } \\
\text { sacrococcygeal } \\
\text { region }\end{array}$ & $\begin{array}{l}\text { Congenital } \\
\text { or early } \\
\text { child- } \\
\text { hood }\end{array}$ & $\begin{array}{l}\text { Pronounced at the age } \\
\text { of } 1 \text { and } 2 \text {, typically } \\
\text { disappears until the } \\
\text { age of } 6 \text { years }\end{array}$ \\
\hline Nevus of Ito & $\begin{array}{l}\text { Shoulder area in the } \\
\text { distribution of the } \\
\text { posterior } \\
\text { supraclavicular } \\
\text { and lateral } \\
\text { cutaneous } \\
\text { brachial nerves }\end{array}$ & $\begin{array}{l}\text { Congenital } \\
\text { or } \\
\text { around } \\
\text { puberty }\end{array}$ & Persistent \\
\hline $\begin{array}{c}\text { Nevus of } \\
\text { Ota }\end{array}$ & $\begin{array}{l}\text { Skin, ocular, and oral } \\
\text { mucosal surfaces } \\
\text { in the distribution } \\
\text { of the ophthalmic } \\
\text { and maxillary } \\
\text { branches of the } \\
\text { trigeminal nerve }\end{array}$ & $\begin{array}{l}\text { Congenital } \\
\text { or } \\
\text { around } \\
\text { puberty }\end{array}$ & Persistent \\
\hline $\begin{array}{l}\text { Melanocyte } \\
\text { hamarto- } \\
\text { ma }\end{array}$ & $\begin{array}{l}\text { Dermatomal } \\
\text { distribution }\end{array}$ & Congenital & Persistent \\
\hline
\end{tabular}

develop a classification scheme, which may help, alongside the main decisive factors such as general circumstances of the initial examination (e. g., experience of the examiner, lighting conditions) and given dermatological conditions of the patient (e. g., diaper rash), to identify cases with a need for recurrent examination.

\section{Material and methods}

All cases of examinations of children on the basis of possible physical or sexual abuse conducted at the Institute of Legal Medicine in Frankfurt/M were included for a time span of 2 years (October 2015-September 2017). Examinations were carried out in an examination room of the Department of child protection/Kinderschutzambulanz with constant lighting and general examination conditions over the time span of 2 years. We adopted an examination regimen with a recommended second examination conducted after a suitable time span of 2 to 6 weeks in cases displaying MS with suspected presence of both, hematoma and MS, to differentiate between these conditions. All examinations, in which Mongolian spots were seen, were documented and archived in a separate register. In addition, a search using the German translation of the words "Mongolian spot," "Mongolian," "dermal melanocytosis" was conducted using the database of written expert opinion statements of the Institute of Forensic Medicine to exclude possible missing entries to the register. The search was limited to statement category 128 (an internal code indicating examinations of children aged $0-18$ years). Furthermore, all files of documentary photographs of cases coded 128 were screened for MS, which had not been listed in the register or described by the keywords used for the database search. For those cases not included in the register and without photographic documentation of the back region, the text files were screened for possible descriptions matching MS without stating the actual word.

In a second step, data of all cases registered under category 128 were extracted from the written forensic statements. We recorded age (in years) at the time of examination (grouped 0 3 years, 4-6 years, combined 0-6 years, and 7-18 years), population group (Caucasian, Mongolid, Negrid), skin types I-VI [26], and gender. Skin type determination was carried out by two independent observers (one physician being a member of the examination team of the institute, the other one working at another institute of legal medicine) determining skin types independently. In cases of interobserver differences, the case was assigned to a skin type by a panel of four of the authors. For descriptive and explorative statistical analysis the statistical software package MedCalc (MedCalc software bvba, Ostend, Belgium) was used. For patients with MS, written expert statements and external documents handed over to the examiners by the police or youth welfare personnel were screened for admission criteria to assess, whether MS had been mistaken for hematoma.

In a third step, cases with documented MS were examined to assess MS location(s), quantity, and dimension(s). From these data, MS constellations found in this cohort were extracted and a classification scheme was developed.

\section{Results}

Within the 2-year period, 253 examinations of children aged $0-18$ were conducted. MS were seen in 26 cases $(10.27 \%)$. In the age group $0-3$ years $(n=98, f=46, m=52), 21$ patients (21.4\%) with MS $(f=7, m=14)$ were identified, whereas in the age group 4-6 years $(n=40, f=23, m=17) 2$ patients $(5 \%$, $f=1, m=1)$, and in the age group $7-18$ years $(n=115, f=57$, $m=58) 3$ patients $(2.6 \%, \mathrm{f}=1, \mathrm{~m}=2$, aged 7,7 , and 10 years, respectively) with MS were seen. While the arithmetic mean for all children examined in this period was $6.1 \pm 4.9$ years, children with MS had highly significantly differing arithmetic mean age of $2.2 \pm 2.6$ years $(t=-3.85 ; p=0.0001)$.

Analysis of skin type classification showed a predominance of type 2 and 3 (type $1=34$, type $2=75$, type $3=79$, type $4=36$, type $5=25$, and type $6=4$ ) (Fig. 1a) with patients displaying MS predominantly found in types 3 and 4 (type $1=$ 0 , type $2=3$, type $3=14$, type $4=6$, type $5=3$, and type $6=$ 0) (Fig. 1b).

Comparative incidence density rate analysis revealed a grouped incidence rate for female patients of 1:14 (95\% CI 1:31-1:7) and for male patients of 1:5 (95\% CI 1:8-1:4), respectively. Incidence rates thus differed highly significantly between 
Fig. 1 Bubble diagrams showing skin type distribution in a the examined collective and $\mathbf{b}$ patients with MS. Skin types are marked as numbers within bubbles
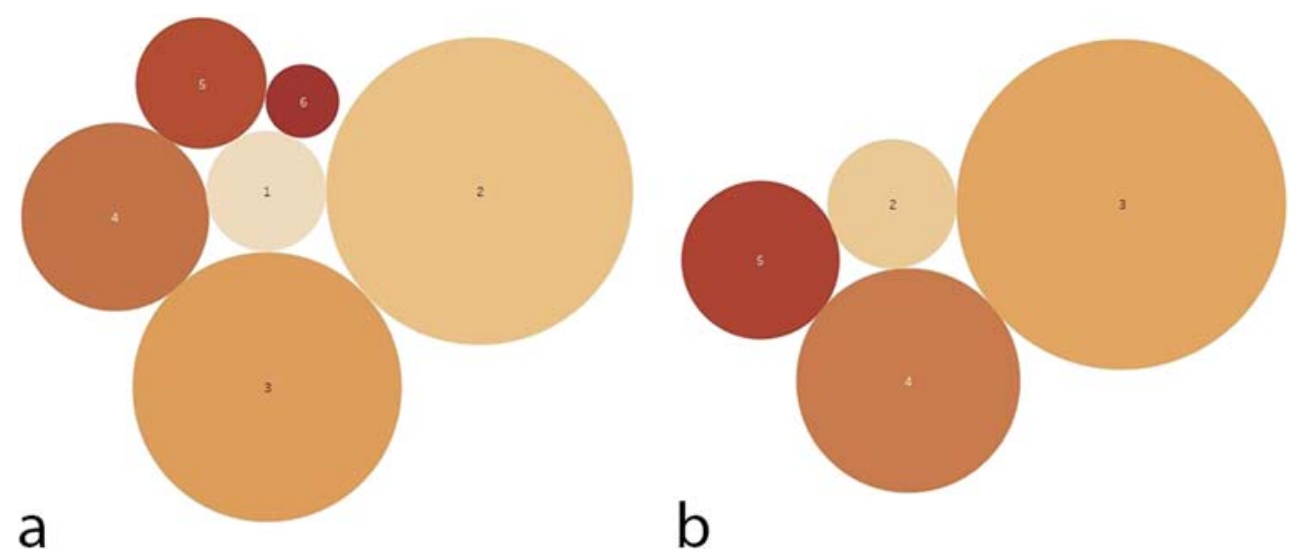

sexes $(p=0.0096$, incidence rate difference $-1: 9$, incidence rate ratio 0.378$)[45,46] . X^{2}$ testing for incidence rate differences in population groups did not show a significant difference $(p=$ 0.225). Comparison of incidence rates for grouped skin types (group $1=$ skin types $1+2$, group $2=$ skin types $3-6$ ) showed a highly significant difference $(p=0.0004$, incidence rate difference - 1:7) with an incidence rate of 1:53 (95\% CI 1:438-1:15) for group 1 and 1:6 (95\% CI 1:10-1:4) for group 2.

Analysis of written expert opinions and information provided by the police and youth welfare personnel showed, that in 19 out of 26 cases, suspected hematoma had been the initial reason for admission (other primary non-exclusive admission criteria: cranial fracture/intracranial hemorrhage $=2$, limb fracture $=3$, thermal injuries $=3$ ). In 2 cases only MS were found, in only 1 case MS had been described as such clinically. In 8 cases, patients had a follow-up examination after 2-6 weeks to clarify the status of hematoma-suspicious findings. In 2 cases, photographs of examinations, that had taken place 3 days and 1 week in advance, were sent in for evaluation after the physical examination.

The inspection of photographic case documentations showed different but distinguishable MS patterns with most cases (in our study) displaying a round to oval sometimes spindle-shaped MS mostly symmetrically arranged at the tip of the intergluteal cleft varying in size between $1 \mathrm{~cm}$ and about $6 \mathrm{~cm}$ in diameter (Fig. 2a,b). Further, MS were seen in varying sizes covering parts of the buttocks (Fig. 2c,d). In one case, the complete buttocks showed blueish discolorations. In a number of cases, MS were seen on parts of the back or as a combination on the buttocks, the back as well as the limbs (Fig. 2e-h). In consideration of these findings, a talking alphanumerically coded classification scheme was developed (Fig. 3), which was intended to encompass all possible MS constellation seen in our study and reported in the literature, to enable a clear risk stratification for the forensic expert, and to produce a speaking classification type, which documents a status, that may later be compared to a given status upon a follow-up examination of a child. Type I consists of MS found on the buttocks, with subtype a found at the tip of the intergluteal cleft, displaying a symmetrical median/paramedian distribution. Subtype b shows MS of varying sizes on the buttocks in an asymmetrical distribution. Existence of more than one subtype or more than one MS of a specific subtype is coded in the alphabetical part of the code, e.g., Type I bb for one MS asymmetrically located at the intergluteal cleft and an additional MS at other parts of the buttocks. Type II shows MS found on other parts of the body, mainly the upper back (subtype a). In our sample, we found one case with MS on a lower limb, which we classified as subtype b (location at lower or upper limbs). In the literature, there has been a report on MS seen on the scalp [25], which may then be subsumed under subtype c (location other than subtype $a$ and $b$ ). Again, multiple MS in a specific region are documented as in type I. Type III is a combination of MS found in two regions, the buttocks and any other part of the body. It may best be coded as, e.g., type III (Ia/II left elbow).

\section{Discussion}

In the present prospective study, examining MS in a collective of 253 children examined due to suspected physical child abuse, MS of varying sizes and shapes were found in $10.27 \%$ (21.4\% age group $0-3$ years) of the cases. This incidence density rate is comparable to those found in Caucasian collectives in earlier studies $[5,13]$. The examined patients comprised Caucasian, negrid, and mongolid ancestry, and thus reflect a typical central European patient spectrum seen in forensic examinations. Arithmetic mean age for all patients of this cohort was just above 6 years, while mean age of patients displaying MS was just above 2 years. This finding is in good accordance to observations, that congenital MS usually disappear until the age of 6 years [25] and are seldomly observed afterward [41]. In this study, a clear preponderance of MS seen in examinations of male patients and patients of grouped skin types 3-6 of the Fitzpatrick classification as compared to grouped skin types 1 and 2 was noted, which has been reported before on the basis of ancestral grouping. 
Fig. 2 Classification of MS: Type Ia MS with common distribution at the tip of the intergluteal cleft (a small, b large). a Small type Ib MS of the right buttock in the presence of a hematoma of the $\mathbf{c}$ left buttock and $\mathbf{d}$ large type $\mathrm{Ib}$ MS of the left buttock. $\mathbf{e}$ Relatively large type IIa MS of the upper back and $\mathbf{f}$ rather small type IIb_left ankle MS of the lower limb. Type III (Ib/IIab_right thigh) MS in a child with three follow-up examinations
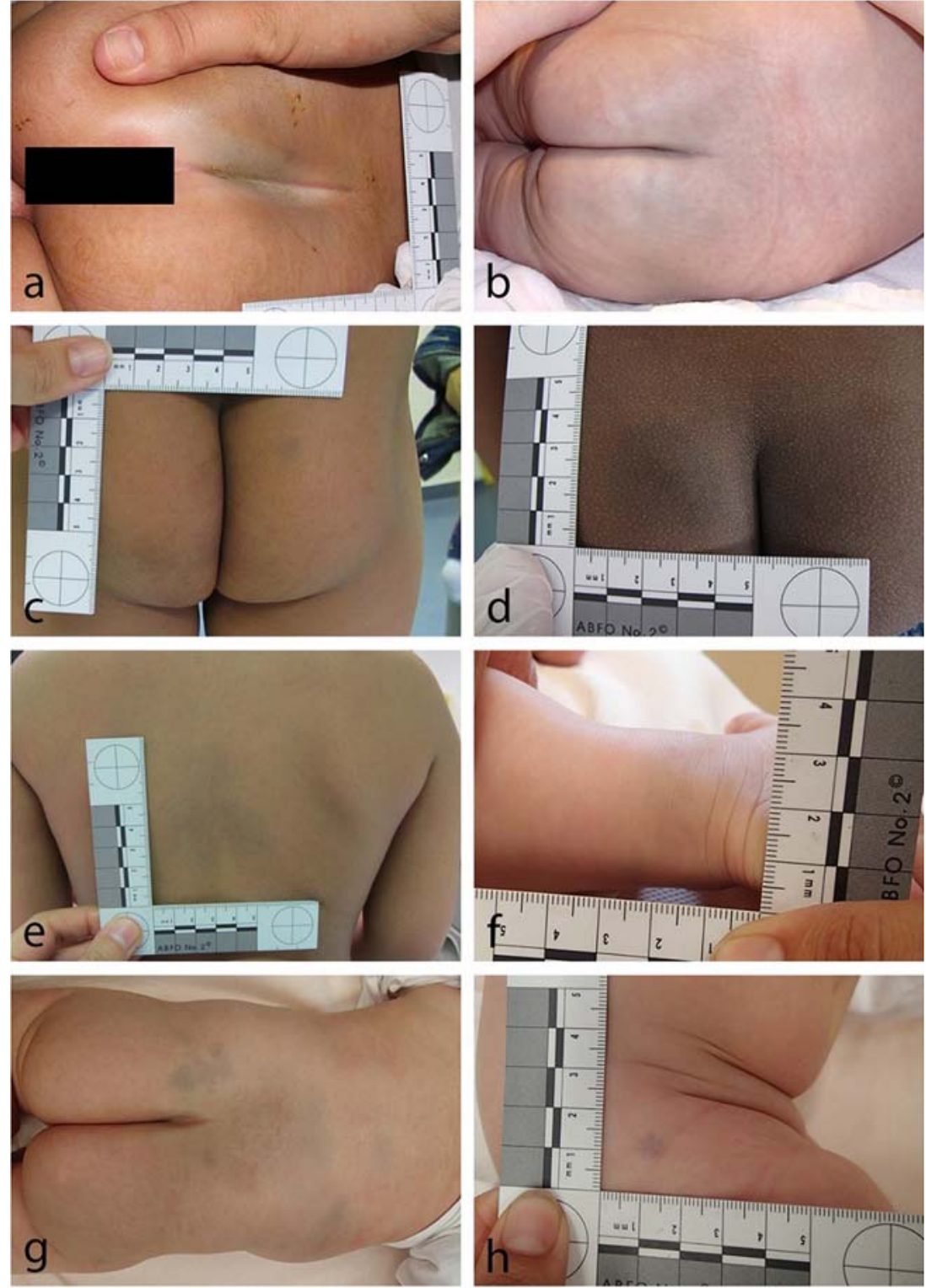

MS are a congenital condition that is well known in the clinical setting. Despite this, MS as a clinical finding in a forensic setting was described in only one case, which may either be due to neglecting a finding seen as nonrelevant or overseeing it. In 2 of the 26 MS cases, MS were the only finding seen during the physical examination ordered on the basis of suspected hematoma, while in 18 cases MS had not been differentiated from hematoma clinically. In 8 of the MS cases, a follow-up examination was assigned, leading to unambiguous assessment of MS as compared to hematoma. This shows that MS may be misinterpreted and that attention of forensic experts needs to be drawn to MS and to follow-up examinations, helping to avoid possible double-misinterpretations (clinically and forensically) with potentially dramatic unjustified consequences for affected families.
On the basis of our findings, we developed a talking alphanumerical classification system of MS intended to enable the clinical and forensic examiner to document a given status for subsequent comparison. As MS are known to be found predominantly on the buttocks and lower back, type 1 resembles this most frequent distribution type with subtype a being centrally located at the tip of the intergluteal cleft comprising various sizes, and subtype $b$ being located on the buttocks or lower back asymmetrically and in various sizes. In order to document the correct numbers, the alphabetical code is repeated for additional MS (e.g., type Iabb). Type II comprises all MS seen on body parts other than the buttocks and lower back, i.e., mainly on the upper back (subtype a) or the remaining body locations (subtype b). In this respect, we had to choose between a clear and decisive classification 
Fig. 3 Classification of MS: type I MS localized in the buttocks region (a type Ia with symmetrical MS at the tip of the intergluteal cleft; $\mathbf{b}$ type Ib with asymmetrical MS of the left buttock; $\mathbf{c}$ type Ibb with two asymmetrical MS). d Type IIa MS located at the upper back, e type IIab with MS located at the upper back and right arm, and $\mathbf{f}$ type IIc with a MS located occipitally; $\mathbf{g}-\mathbf{i}$ type III MS displaying combinations of type I and type II MS
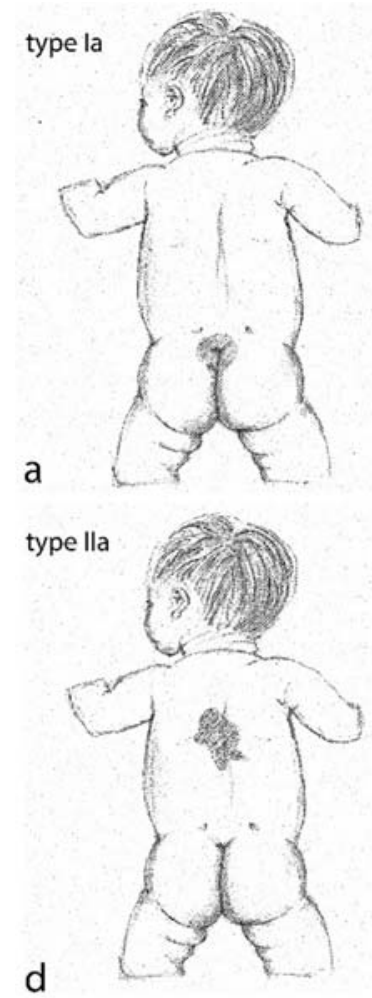

b
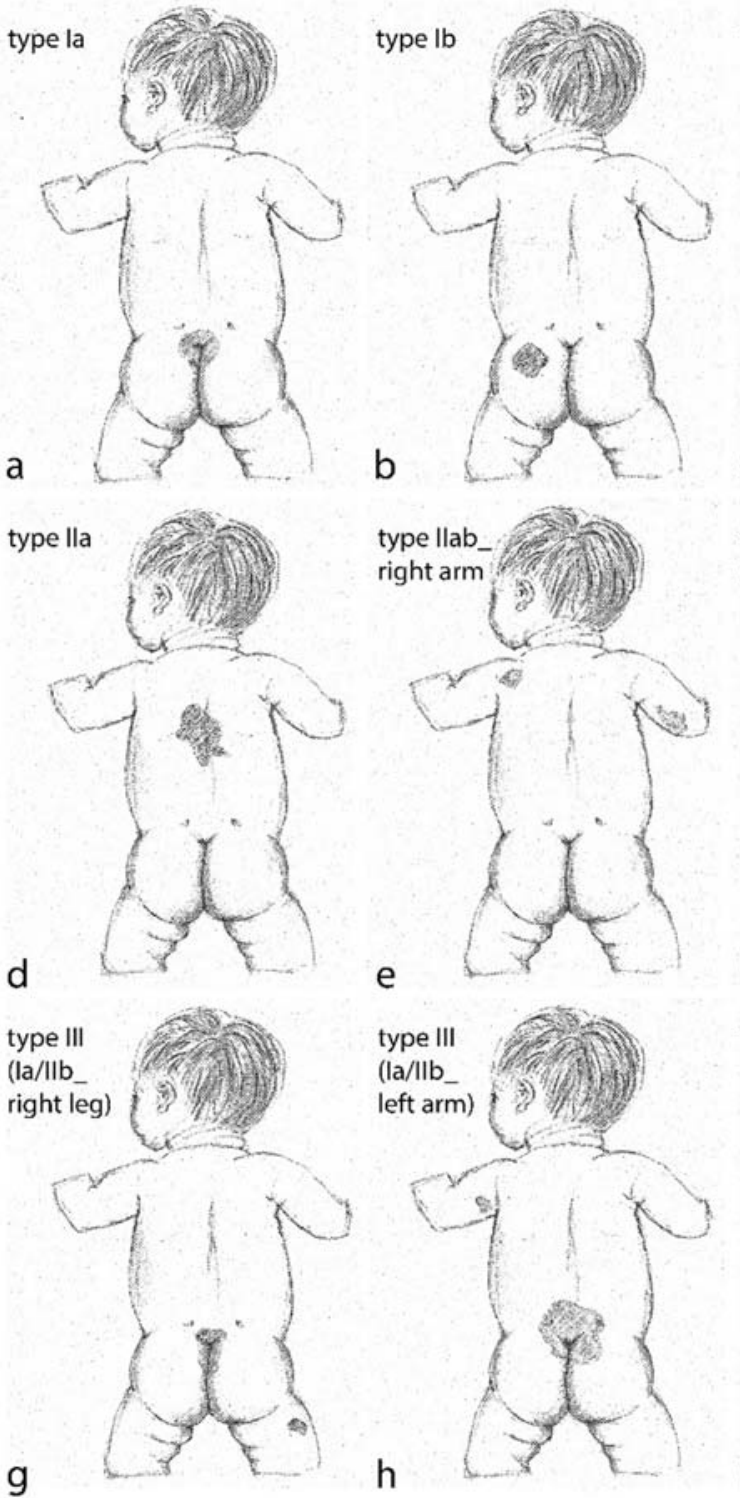
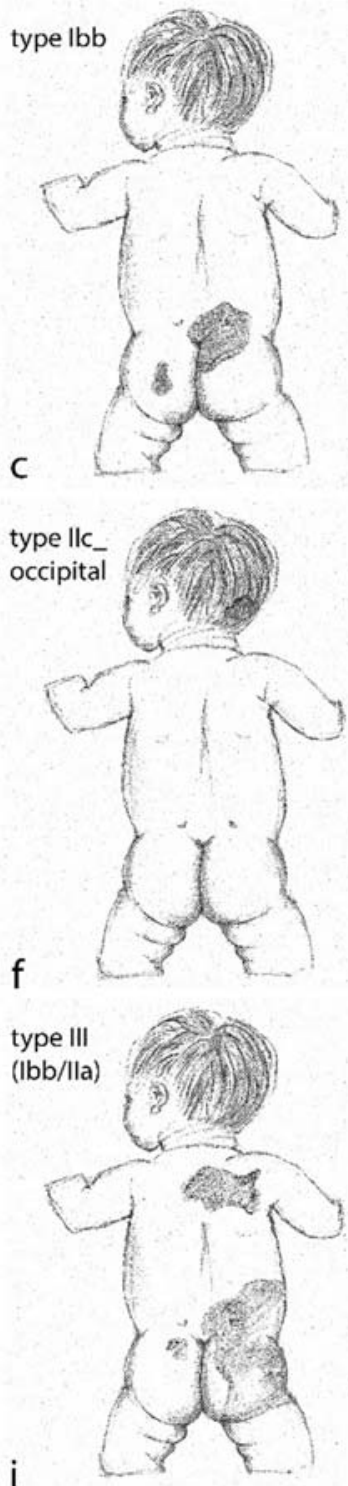

leaving some anatomical data to be added and a classification with a very detailed, yet confusing anatomical code. For practical purposes, we suggest to add anatomical information on the specific location in these rare cases (e.g., type IIb_left ankle). Type III had to be included to clearly mark a combination of types I and II, which may be documented as type III (Ia/IIb_left ankle) for a patient showing MS at the tip of the intergluteal cleft as well as the left ankle. A coded description of MS area was discussed but not deemed appropriate, since MS fade out over time and may thus be seen covering less skin area at an examination conducted after a relevant time span (of e.g., 2 years). At least in our collective, it was possible to differentiate between inconspicuous findings (type Ia) and those, in which a follow-up examination seemed advisable in the absence of further information indicating MS persistence at a specific location (types Ib, II, III), e.g., hospital reports or photographic documentations. Nevertheless, a decision, whether a second examination seems advisable and should be exerted, cannot be solely based on a classification scheme but has to include the main decisive factors such as the experience of the examiner, general examination conditions of the first examination such as the lighting, as well as given dermatological conditions of the patient in the respective areas, e.g., a diaper rash. 
Acknowledgements Open Access funding provided by Projekt DEAL.

Open Access This article is licensed under a Creative Commons Attribution 4.0 International License, which permits use, sharing, adaptation, distribution and reproduction in any medium or format, as long as you give appropriate credit to the original author(s) and the source, provide a link to the Creative Commons licence, and indicate if changes were made. The images or other third party material in this article are included in the article's Creative Commons licence, unless indicated otherwise in a credit line to the material. If material is not included in the article's Creative Commons licence and your intended use is not permitted by statutory regulation or exceeds the permitted use, you will need to obtain permission directly from the copyright holder. To view a copy of this licence, visit http://creativecommons.org/licenses/by/4.0/.

\section{References}

1. Sethi D, Bellis M, Hughes K, Gilbert R, Mitis F, Galea G (2013) World Health Organization. In: European report on preventing child maltreatment http://www.euro.who.int/ data/assets/pdf_file/0019/217018/European-Report-onPreventing-Child-Maltreatment.pdf.

2. Zembowicz A, Mihm MC (2004) Dermal dendritic melanocytic proliferations: an update. Histopathology 45:433-451

3. Lucky AW (2015) Transient benign cutaneous lesions in the newborn. In: Eichenfield LF, Frieden IJ, Zaenglein A, Mathes E (eds) Textbook of neonatal and infant dermatology, 3rd edn. Elsevier Saunders, London, New York, Oxford, Philadelphia, St. Louis, Sydney, Toronto, p 72

4. Cordova A (1981) The Mongolian spot: a study of ethnic differences and a literature review. Clin Pediatr (Phila) 20:714-719

5. Rivers JK, Frederiksen PC, Dibdin C (1990) A prevalence survey of dermatoses in the Australian neonate. J Am Acad Dermatol 23: 77-81

6. Karvonen SL, Vaajalahti P, Marenk M, Janas M, Kuokkanen K (1992) Birthmarks in 4346 Finnish newborns. Acta Derm Venereol 72:55-57

7. Tsai FJ, Tsai CH (1993) Birthmarks and congenital skin lesions in Chinese newborns. J Formos Med Assoc 92:838-841

8. Magaña-García M, González-Campos N (1997) Skin lesions in a 1, 000 newborns. A case and control study. Gac Med Mex 133:407411

9. Egemen A, Ikizoğlu T, Ergör S, Mete Asar G, Yilmaz O (2006) Frequency and characteristics of Mongolian spots among Turkish children in Aegean region. Turk J Pediatr 48:232-236

10. Shih IH, Lin JY, Chen CH, Hong HS (2007) A birthmark survey in 500 newborns: clinical observation in two northern Taiwan medical center nurseries. Chang Gung Med J 30:220-225

11. Ferahbas A, Utas S, Akcakus M, Gunes T, Mistik S (2009) Prevalence of cutaneous findings in hospitalized neonates: a prospective observational study. Pediatr Dermatol 26:139142

12. Reza AM, Farahnaz GZ, Hamideh S, Alinaghi SA, Saeed Z, Mostafa H (2010) Incidence of Mongolian spots and its common sites at two university hospitals in Tehran, Iran. Pediatr Dermatol 27:397-398

13. Kanada KN, Merin MR, Munden A, Friedlander SF (2012) A prospective study of cutaneous findings in newborns in the United States: correlation with race, ethnicity, and gestational status using updated classification and nomenclature. $\mathrm{J}$ Pediatr 161:240-245

14. Gupta D, Thappa DM (2013) Mongolian spots-a prospective study. Pediatr Dermatol 30:683-688

15. Haveri FT, Inamadar AC (2014) A cross-sectional prospective study of cutaneous lesions in newborn. ISRN Dermatol 20:360590

16. Shehab MM, Youssef DM, Khalil MM (2015) Prevalence of cutaneous skin lesions in neonatal intensive care unit: a single center study. J Blin Neonatol 4:169-172

17. Punuru L, Badabagni P, Dasika S, Bendapudi RV (2016) Clinical study of cutaneous manifestations in neonates. IJCED 2:98-101

18. Sandeep B, Susheela C, Keerthi S (2016) Cutaneous lesions in newborn babies: a hospital based study. Int J Sci Stud 4:43-49

19. Budair F, Aljabre S, Alquorain N, Alnafea N, Aljabre A, Alburaey A (2017) Survey of cutaneous findings in newborns in Saudi Arabia. J Dermatol Dermatol Surg 21:53-57

20. Kikuchi I, Inoue S (1980) Natural history of the Mongolian spot. J Dermatol 7:449-450

21. Ito M (1954) Studies on melanin XXII. Nevus fuscocaeruleus acromio-deltoideus. Tohoko J Exper Med 60:10

22. Ota M, Tanino H (1939) Nevus fusco-caeruleus ophthalmomaxillaris. Tokyo Med J 63:1243-1245

23. Burkhart CG, Gohara A (1981) Dermal melanocyte hamartoma. A distinctive new form of dermal melanocytosis. Arch Dermatol 117: 102-104

24. AlJasser M, Al-Khenaizan S (2008) Cutaneous mimickers of child abuse: a primer for pediatricians. Eur J Pediatr 167:1221-1230

25. Leung AK, Kao CP (1999) Extensive Mongolian spots with involvement of the scalp. Pediatr Dermatol 16:371-372

26. Fitzpatrick TB (1988) The validity and practicality of sun-reactive skin types I through VI. Arch Dermatol 124:869-871

27. Leung AK, Robson WL (2008) Superimposed Mongolian spots. Pediatr Dermatol 25:233-235

28. Musumeci ML, Lacarrubba F, Santagati C, Micali G (2013) Multiple and superimposed Mongolian spots. BMJ Case Rep 6: 2013. https://doi.org/10.1136/bcr-2013-200740

29. Ahn JS, Kim SD, Hwang JH, Youn SW, Kim KH, Park KC (1998) Halo-like disappearance of Mongolian spot combined with café au lait spot. Pediatr Dermatol 15:70-71

30. Ashrafi MR, Shabanian R, Mohammadi M, Kavusi S (2006) Extensive Mongolian spots: a clinical sign merits special attention. Pediatr Neurol 34:143-145

31. Grant BP, Beard JS, de Castro F, Guiglia MC, Hall BD (1998) Extensive Mongolian spots in an infant with Hurler syndrome. Arch Dermatol 134:108-109

32. Weissbluth M, Esterly NB, Caro WA (1981) Report of an infant with GM1 gangliosidosis type I and extensive and unusual Mongolian spots. Br J Dermatol 104:195-200

33. Kumar Bhardwaj N, Khera D (2016) Mongolian Spots in GM1 Gangliosidosis. Indian Pediatr 53:1133

34. Bersani G, Guerriero C, Ricci F, Valentini P, Zampino G, Lazzareschi I, Antuzzi D, Rigante D (2016) Extensive irregular Mongolian blue spots as a clue for GM1 gangliosidosis type 1. J Dtsch Dermatol Ges 14:301-302

35. Mimouni-Bloch A, Finezilber Y, Rothschild M, Raas-Rothschild A (2016) Extensive Mongolian spots and lysosomal storage diseases. J Pediatr 170:333-3e1

36. Ochiai T, Suzuki Y, Kato T, Shichino H, Chin M, Mugishima H, Orii T (2007) Natural history of extensive Mongolian spots in mucopolysaccharidosis type II (Hunter 
syndrome): a survey among 52 Japanese patients. J Eur Acad Dermatol Venereol 21:1082-1085

37. Su F, Li F, Jin HZ (2010) Extensive Mongolian spots in a child with mucolipidosis II. Int J Dermatol 49:438-440

38. Pinto LIB, Richanevski N, Paskulin GA, Mendez HMM (1990) Extensive Mongolian spots and inborn errors of metabolism. Am J Hum Genet 49:156

39. Gupta D, Thappa DM (2013) Mongolian spots: how important are they? World J Clin Cases 1:230-232

40. Leung AK (1988) Mongolian spots in Chinese children. Int J Dermatol 27:106-108

41. Leung AK, Kao CP, Leung AA (2005) Persistent Mongolian spots in Chinese adults. Int J Dermatol 44:43-45

42. Asnes RS (1984) Buttock bruises-Mongolian spot. Pediatrics 74: 321
43. Oates RK (1984) Overturning the diagnosis of child abuse. Arch Dis Child 59:665-666

44. Hammer U, Boy D, Rothaupt D, Büttner A (2015) Distinction between forensic evidence and dermatological findings. J Forensic Leg Med 33:1-4

45. Sahai H, Khurshid A (1996) Statistics in epidemiology: methods, techniques, and applications. CRC Press, Inc., Boca Raton, USA

46. Campbell I (2007) Chi-squared and Fisher-Irwin tests of two-bytwo tables with small sample recommendations. Statistics in Medicine 26:3661-3675

Publisher's note Springer Nature remains neutral with regard to jurisdictional claims in published maps and institutional affiliations. 